\title{
Compliance with Continuous Positive Airway Pressure in Patients with Obstructive Sleep Apnea
}

\author{
Min Young Seo, MD, Seung Hoon Lee, MD, PhD \\ Division of Rhinology \& Sleep Medicine, Department of Otorhinolaryngology-Head and Neck Surgery, Korea University Ansan Hospital, Korea University \\ College of Medicine, Ansan, Korea
}

\begin{abstract}
Obstructive sleep apnea (OSA) is caused by upper airway obstruction during sleep and increases risk for stroke and cardiovascular morbidity. It is also related to excessive daytime sleepiness and cognitive dysfunction in affected adults. Additionally, OSA also affects children, manifesting as growth retardation and neurobehavioral abnormalities. Continuous positive airway pressure (CPAP) therapy is the treatment of choice for moderate to severe disease in adults and in some of the pediatric population. CPAP therapy reduces daytime sleepiness, improves quality of life, and reduces risk for cardiovascular morbidity and mortality in individuals with OSA. Although CPAP therapy is effective in these patients, it has significant limitations regarding compliance. Accordingly, the purpose of this review was to investigate factors impacting compliance with treatment including socioeconomic/demographic characteristics, nasal obstruction, previous upper airway surgery, severity of OSA, psychological factors, support/intervention of CPAP, and device-related factors. Additionally, factors associated with CPAP compliance in children are also discussed.
\end{abstract}

Sleep Med Res 2020;11(1):7-14

Key Words Sleep apnea syndromes, Continuous positive airway pressure, Patient compliance.

\section{INTRODUCTION}

Received: April 15, 2020

Revised: May 1, 2020

Accepted: May 3, 2020

Correspondence

Seung Hoon Lee, MD, PhD

Division of Rhinology \& Sleep Medicine,

Department of Otorhinolaryngology-

Head and Neck Surgery,

Korea University Ansan Hospital,

Korea University College of Medicine,

123 Jeokgeum-ro, Danwon-gu,

Ansan 15355, Korea

Tel $\quad+82-31-412-5170$

Fax +82-31-412-5174

E-mail shleeent@korea.ac.kr

ORCID

Min Young Seo

https://orcid.org/0000-0002-1287-6961

Seung Hoon Lee

https://orcid.org/0000-0001-7811-2692

(C) This is an Open Access article distributed under the terms of the Creative Commons Attribution Non-Commercial License (https://creativecommons.org/licenses/by-nc/4.0) which permits unrestricted non-commercial use, distribution, and reproduction in any medium, provided the original work is properly cited.
Obstructive sleep apnea (OSA) is characterized by repetitive upper airway obstruction and failure of normal ventilation that causes hypoxemia and arousal during sleep. The estimated prevalence of OSA is approximately $22 \%$ (9-37\%) in adult males and $17 \%$ (4-50\%) in adult females, and $1-5 \%$ in the general pediatric population $[1,2]$. OSA increases the risk for stroke and cardiovascular disease from hypertension, and endothelial dysfunction because of sympathetic activation. It is also related to excessive daytime sleepiness and cognitive dysfunction in affected adults [3-5]. Also, OSA is a cause of growth retardation and neurobehavioral abnormalities in children [1].

Since the first report describing continuous positive airway pressure (CPAP) therapy as an effective treatment for OSA in 1981 [6], it has been regarded as first-line therapy in individuals with moderate to severe OSA [7]. CPAP treatment reduces daytime sleepiness and improves quality of life, and also reduces cardiovascular morbidity and mortality [8-10]. Although CPAP is an effective treatment modality in patients with OSA, it has significant limitations in terms of compliance. In various studies, the terms "adherence" and "compliance" are often used interchangeably, and the definition of these terms is regarded as the average number of hours of nightly use. Additionally, according to the Centers for Medicare and Medical Services, adequate adherence or compliance of CPAP is defined as using a CPAP device for $\geq 4$ hours daily and $\geq 70 \%$ of nights [11]. In this review, the terms are unified and hereafter referred to as "compliance." It has been reported that approximately $29-83 \%$ of patients are non-compliant with CPAP treatment [12], with the suboptimal use of CPAP also identified in the pediatric population 
$[13,14]$. Thus, many investigators have conducted studies that have focused on determining the factors that impact CPAP compliance, and have also identified effective strategies to encourage better compliance. The purpose of this review was to organize studies investigating compliance with CPAP therapy according to various factors including socioeconomic/demographic characteristics, nasal obstruction, previous oropharyngeal surgery, severity of OSA, psychological factors, support/intervention of CPAP, and device-related factors (Table 1). Additionally, we also investigated factors associated with CPAP compliance in children (Table 2).

\section{SOCIOECONOMIC/DEMOGRAPHIC CHARACTERISTICS}

Several studies have assessed CPAP compliance according to various characteristics including age, sex, ethnicity, and socioeconomic status (SES). Kohler et al. [15] conducted a large study using the Kaplan-Meier survival analyses for long-term [median 3.9 (interquartile range 1.5-6.9 years)] compliance in 639 patients undergoing CPAP treatment. The authors reported that age and sex were not significantly associated with CPAP compliance. In a prospective cohort study with 221 patients using CPAP six months after initial treatment, Gulati et al. [16] did not find associations between compliance with CPAP therapy and age, sex, or education level. Another study that performed the Cox proportional hazard analysis among 163 patients also reported that age did not affect compliance, although female sex [adjusted relative risk 2.8 (mean $1.4 \pm 5.4$ ); $\mathrm{p}=0.002$ ] and body mass index $\leq 30 \mathrm{~kg} / \mathrm{m}^{2}$ [adjusted relative risk 2.2 (mean, $1.2 \pm 4) ; p=0: 006]$ were predictive factors for non-compliance [17]. However, in a randomized, double-blind, sham-controlled trial with 138 patients with moderate-to-severe OSA over eight

Table 1. Factors influence in CPAP compliance in adults

\begin{tabular}{|c|c|}
\hline Factor & Result \\
\hline \multicolumn{2}{|l|}{ Socioeconomic/demographic characteristics } \\
\hline Age & Controversial \\
\hline Sex & Controversial \\
\hline Ethnicity & African Americans showed lower compliance than Caucasians \\
\hline Socioeconomic status & High socioeconomic level is associated with adequate compliance \\
\hline \multicolumn{2}{|l|}{ Nasal obstruction } \\
\hline $\begin{array}{l}\text { Obstructive nasal disease } \\
\text { (nasal septal deviation, inferior turbinate } \\
\text { hypertrophy, nasal valve collapse) }\end{array}$ & Associated with poor compliance \\
\hline Chronic rhinosinusitis & Limited data on the effects of ESS on sleep apenea \\
\hline Septoplasty, turbinoplasty & Nasal surgery improves compliance \\
\hline Intranasal steroid treatment & No benefit \\
\hline \multicolumn{2}{|l|}{ Prior oropharyngeal surgery } \\
\hline UPPP & Can reduce the pressure and might increase compliance \\
\hline \multicolumn{2}{|l|}{ Severity of OSA } \\
\hline AHI, RDI, ODI, CT90, nadir $\mathrm{SpO}_{2}$ & As worse the OSA, compliance was increased \\
\hline Psychological factors & Self-efficacy before initiation increases compliance \\
\hline \multicolumn{2}{|l|}{ Support/intervention } \\
\hline Reinforced education & Controversial \\
\hline Intensive support & Controversial \\
\hline Telemonitoring care & Could increase the compliance \\
\hline Explanation with PSG viewing & Explanation of disease severity with viewing their PSG data could increase the compliance \\
\hline \multicolumn{2}{|l|}{ Device factors } \\
\hline Pressure delivery mode & Controversial in APAP vs. CPAP and no difference in BiPAP vs. CPAP \\
\hline Oral vs. nasal interface & Controversial but initial mask selection can influence the compliance \\
\hline Heated humidity & Controversial \\
\hline
\end{tabular}

ESS: endoscopic sinus surgery, UPPP: uvulopalatopharyngoplasty, OSA: obstructive sleep apnea, AHI: apnea-hypopnea index, RDI: respiratory disturbance index, ODI: oxygen desaturation index, CT90: the percentage of duration with $\mathrm{O}_{2}$ desaturation of $<90 \%$, PSG: polysomnography, APAP: auto-titrating positive airway pressure, CPAP: continuous positive airway pressure, BiPAP: bilevel positive airway pressure 
Table 2. Factors influence in CPAP compliance in children

\begin{tabular}{lc}
\hline \multicolumn{1}{c}{ Factor } & \multicolumn{1}{c}{ Result } \\
\hline $\begin{array}{l}\text { Socioeconomic/demographic characteristics } \\
\text { Age }\end{array}$ & Controversial \\
Sex & Not associated but one study \\
& reported that female sex is \\
& associated with better compliance \\
Maternal education level & Controversial \\
Severity of OSA & Not associated but one study \\
& reported that higher baseline \\
& AHI showed better compliance \\
Psychological factors & Self-efficacy before initiation \\
& increases compliance \\
\hline
\end{tabular}

OSA: obstructive sleep apnea, AHI: apnea-hypopnea index, CPAP: continuous positive airway pressure

weeks of CPAP treatment, May et al. [18] reported that, according to adjusted linear analysis, elderly age was strongly associated with improvement in adherence $\{35 \mathrm{~min} /$ decade [95\% confidence interval (CI) 13-57 min/decade]\}. As such, we found that the impact of age and sex on compliance with CPAP treatment remains controversial. Various studies have reported that SES was significantly associated with CPAP compliance. Longterm unemployment, residing in socioeconomically deprived areas, low income level, and living alone were associated with significantly lower compliance with CPAP therapy [16,19-24]. A retrospective study that included 266 OSA patients who underwent CPAP therapy reported that compliance was associated with the neighborhood SES level, independent of other characteristics [24]. Additionally, Gangnadoux et al. [22] reported that retired patients demonstrated higher compliance than those currently working [odds ratio (OR) 1.414 (95\% CI 1.097$1.821) ; \mathrm{p}=0.007$ ]. Several studies have reported that African Americans demonstrated lower compliance with CPAP therapy than Caucasians $[17,18,20,25,26]$. In contrast, however, a retrospective study that included 128 African American patients and 102 Caucasian OSA patients reported no racial differences in CPAP compliance [27].

\section{NASAL OBSTRUCTION}

Many patients complain of nasal discomfort including nasal dryness, sneezing, post-nasal drip, and nasal congestion during CPAP treatment [28]. Disease in these individuals will worsen because of various nasal pathologies including nasal septal deviation, inferior turbinate hypertrophy, and nasal valve collapse [29]. These types of nasal discomfort may play a role in intolerance to CPAP therapy. A prospective study of 77 OSA patients who underwent nasal CPAP treatment reported that higher nasal resistance was a significant factor in CPAP non-acceptance
$\left(\mathrm{OR}+0.1 \mathrm{~Pa} / \mathrm{cm}^{3} / \mathrm{s}: 1.48 ; \mathrm{p}=0.002\right)[30]$. Inoue et al. [31] reported that nasal disease or total nasal resistance (TNR) were crucial factors for the discontinuation of CPAP in the early stage $\left[T N R \geq 0.4 \mathrm{~Pa} / \mathrm{cm}^{3} / \mathrm{s}: \exp (\mathrm{B}) 0.188 ; \mathrm{p}=0.011\right.$ ], and long-term CPAP compliance could be predicted from early CPAP compliance [initial use rate $\geq 70$ : $\exp$ (B) 6.714; $p<0.001$ ]. Similar results were reported by Park et al. [32] in a retrospective study with 47 OSA patients who received CPAP treatment [adherent $(\mathrm{n}=24)$, non-adherent $(\mathrm{n}=23)]$. A higher grade of septal deviation and inferior turbinate hypertrophy were observed more in the non-adherent group than the adherent group, with a difference that was statistically significant. Thus, the authors recommend that nasal diseases are adequately treated before CPAP initiation for better long-term compliance. Treatment targeted at improving increased nasal resistance may also improve compliance with CPAP therapy [29]. Several studies have reported that nasal surgery can improve compliance with CPAP therapy. Camacho et al. [33] reported that the regular use of CPAP was $38.7 \%$ in patients before nasal surgery and improved to $90.2 \%$ after nasal surgery, and $89.1 \%$ of patients not using CPAP subsequently accepted it after nasal surgery in a subgroup analysis. In a randomized double-blind, placebo-controlled study with 22 patients [case $(n=17)$ vs. control $(n=5)$ ], Powell et al. [34] investigated the effect(s) of temperature-controlled radiofrequency (TCRF) reduction for turbinate hypertrophy on CPAP compliance. They concluded that TCRF turbinate treatment improved compliance with CPAP therapy (mean compliance change $-0.04 \pm 0.05$ vs. $0.06 \pm 0.12 ; p=0.007)$. Another study reported similar results with septoplasty plus inferior turbinoplasty, with CPAP compliance improving after surgery $(0.5 \mathrm{~h} /$ night to $3.9 \mathrm{~h} /$ night) in 20 OSA patients intolerant to nasal CPAP therapy [34]. Also, Mickelson [29] reported that there were limited data regarding the effect of endoscopic sinus surgery (ESS) on sleep apnea; as such, it is unclear if ESS only had direct effect on nasal resistance. Nevertheless, the authors suggest that it may have a secondary benefit in reducing sinonasal inflammation.

We also reviewed studies investigating the effect of topical nasal steroid on CPAP compliance. A prospective randomized study with 125 OSA patients who tolerated nasal CPAP therapy via nasal mask reported that application of topical nasal steroid(s) yielded no benefit to CPAP compliance four weeks after treatment [35]. Another a randomized, double-blinded, placebo-controlled study reported the same result after four weeks of treatment with topical fluticasone propionate [36].

\section{PREVIOUS OROPHARYNGEAL SURGERY}

Oropharyngeal surgery includes uvulopalatopharyngoplasty (UPPP), another crucial treatment modality for mild and moderate OSA. However, the reported success rate in unselected pa- 
tients has been as low as $40 \%$ [37]. Thus, physicians should consider additional-if not alternative - CPAP treatment for patients in whom surgery is ineffective. A prospective cross-sectional study with 47 OSA patients undergoing CPAP therapy reported that upper airway occlusion caused by tonsillar hypertrophy, may increase pressure in CPAP therapy. This study suggests that correcting this problem may be effective in increasing CPAP compliance [38]. Accordingly, we reviewed several studies that compared CPAP compliance between patients with and without history of oropharyngeal surgery for OSA. Hong et al. [39] retrospectively conducted such an evaluation of 86 patients and reported that the CPAP compliance rate was higher in the surgery group than in the control group three months after initiation of CPAP treatment, although the difference was statistically insignificant $(87.5 \%$ vs. $60.7 \%$, respectively; $p=0.243)$. However, the mean daily hours of usage was significantly higher in the surgery compared with the control group $(6.39 \mathrm{~h} /$ day vs. $4.73 \mathrm{~h} /$ day, respectively; $\mathrm{p}=0.007$ ). Similarly, Azbay et al. [40] reported that among 67 CPAP-intolerant patients, 32 tolerated CPAP well after oropharyngeal surgery. Additionally, results from the two other studies investigating CPAP pressure reduction after oropharyngeal surgery also support increases in CPAP compliance $[38,41]$.

\section{SEVERITY OF OSA}

We found several studies reporting that the severity of OSA according to apnea hypopnea index (AHI), respiratory disturbance index (RDI), nocturnal desaturation, and oxygen desaturation index (ODI) could affect compliance with CPAP treatment. Riachy et al. [42] conducted a cross-sectional cohort study with 138 OSA patients who underwent CPAP treatment and reported that mean RDI $(33.41 \pm 24.70$ vs. $22.96 \pm 19.28 ; \mathrm{p}=0.028)$ and ODI ( $24.86 \pm 23.18$ vs. $14.64 \pm 18.83 ; \mathrm{p}=0.023)$ were significantly higher, and nadir oxygen saturation $(80.33 \pm 10.86 \%$ vs. $85.18 \pm 16.88 \% ; \mathrm{p}=0.017$ ) was significantly lower in the compliant group three months after initiation of CPAP therapy. They also reported that mean RDI (34.90 \pm 24.40 vs. $27.00 \pm$ 22.90; $\mathrm{p}=0.050)$ and ODI $(26.80 \pm 24.60$ vs. $18.10 \pm 20.60 ; \mathrm{p}=$ 0.029 ) were significantly higher in the compliant group at the end of the observation. Additionally, higher ODI at diagnosis [hazard ratio (HR) $0.98 ; \mathrm{p}=0.048$ ] was independently associated with short-term compliance with CPAP therapy. CamposRodriquez et al. [43] conducted a prospective cross-sectional study with 357 non-sleepy OSA patients who received CPAP treatment and reported that AHI [46.5 (95\% CI 33.0-63.0) vs. 33.0 (95\% CI 26.5-52.5); $\mathrm{p}<0.001$ ] and the percentage of duration with oxygen desaturation $<90 \%$ [10.0 (95\% CI 2.2-27.0) vs. 5.0 (95\% CI 1.1-15.0); $\mathrm{p}<0.001$ ] were significantly higher in the compliant group. Baratta et al. [44] conducted a prospective study with 295 patients with moderate or severe OSA syndrome
(OSAS; AHI $\geq 15$ events/h) with a median follow-up of 74.8 months and reported that lower severity of OSAS [HR 0.66 (95\% CI 0.46-0.94); $\mathrm{p}<0.023$ ] was an independent predictor of noncompliance with CPAP therapy. Also, a large cohort study performed by Kohler et al. [15] reported that ODI was independently associated with long-term compliance with CPAP [HR per 1 event, 0.97 (95\% CI 0.96-0.98); $\mathrm{p}<0.001$ ]. Thus, various parameters reflecting the severity of OSA appeared to be significantly associated with compliance to CPAP therapy; more specifically, as disease severity increased, compliance also increased.

\section{PSYCHOLOGICAL FACTORS}

This category includes perception of the risk for disease, outcome expectancy, and self-efficacy of treatment. Stepnowsky et al. [45] initially assessed pretreatment perception of outcome expectations and treatment self-efficacy variables based on the social cognitive theory. The authors reported that these variables, measured one week after initiation of CPAP therapy, were significantly associated with one-month CPAP compliance. Additionally, Weaver et al. [46] developed the self-efficacy in sleep apnea (SEMSA) scale, with supplementation of limitations of the prior study. Baron et al. [47] reported that self-efficacy was significantly associated with CPAP use $[r=0.08$, standard error $(\mathrm{SE})=0.03, \mathrm{p}<0.01]$, and higher treatment self-efficacy positively affected CPAP use. Sawyer et al. [48] conducted a prospective study with 66 OSA patients undergoing CPAP treatment and reported that, although baseline SEMSA domains did not influence CPAP use, post-education self-efficacy was positively affected at one week and one month of CPAP use. Recently, Philip et al. [49] conducted a retrospective cross-sectional study with 288 OSA patients undergoing CPAP therapy and reported that SEMSA self-efficacy score was significantly associated with mean daily CPAP use $(\mathrm{b}=0.581, \mathrm{SE}=0.174 ; \mathrm{p}<0.001)$.

\section{SUPPORT/INTERVENTION OF CPAP}

We found several studies investigating patient support and intervention that could affect CPAP compliance; however, the results were conflicting. In a prospective randomized controlled study with 112 patients with severe OSA, Meurice et al. [50] reported that oral and written explanations and multiple home visits (i.e., reinforced education) did not demonstrate superiority over simple oral explanation and a home visit (i.e., standard education) for CPAP therapy compliance. Additionally, Hui et al. [51] and Bouloukaki et al. [52] also reported that augmentation of CPAP education, or support or intensive follow-up, did not increase compliance with CPAP therapy. In contrast, Hoy et al. [53] reported that patients who received intensive CPAP support demonstrated higher CPAP usage than the standard 
support group six months after initiation of treatment (5.4 \pm 0.3 $\mathrm{h} /$ night vs. $3.8 \pm 0.4 \mathrm{~h} /$ night; $\mathrm{p}=0.003$ ). Also, in a meta-analysis investigating telemonitoring (TM) care and compliance with CPAP therapy in 19 randomized controlled studies that included 2,464 patients, Chen et al. [54] reported that CPAP compliance was significantly higher in the TM care group than the control group [mean difference $0.68 \mathrm{~h}$ (95\% CI 0.48-0.89 h); $\mathrm{I}^{2}=$ $49 \%$ ]. Jurado-Gamez et al. [55] also reported that the patient group, educated about the importance of CPAP adherence while viewing results of their polysomnography (PSG) data before treatment, demonstrated better compliance than the control group six months after the initiation of CPAP treatment $(86 \%$ vs. $76 \%$, respectively; $p=0.031$ ). Additionally, they found that the number of hours of CPAP use was also significantly higher in the intervention group $(5 \pm 1.8 \mathrm{~h} /$ night vs. $4.3 \pm 1.7 \mathrm{~h} /$ night, respectively; $\mathrm{p}=0.001$ ). A similar study performed by Falcone et al. [56] reported that PSG chart viewing by OSA patients increased compliance with CPAP therapy at one month ( $94 \%$ vs. $69 \%$; $<<0.001$ ), three months ( $97 \%$ vs. $71 \%$; $<<0.001$ ), and 12 months $(97 \%$ vs. $74 \%$; $\mathrm{p}<0.001)$ after initiation of CPAP treatment. Thus, we suggest that, although the effects of augmented patient education and intervention with CPAP compliance are controversial, explanation of disease severity and having patients view their PSG data, combined with TM care, may increase compliance with CPAP therapy.

\section{DEVICE-RELATED FACTORS}

We found several studies which have evaluated the effects of pressure delivery methods on compliance. A study conducted by Massie et al. [57] reported that auto-titrating positive airway pressure (APAP) have shown higher average daily used hours than CPAP $(306 \pm 114 \mathrm{~min} / 24 \mathrm{~h}$ vs. $271 \pm 115 \mathrm{~min} / 24 \mathrm{~h}, \mathrm{p}<$ 0.005). Additionally, Konermann et al. [58] reported that APAP have shown higher average weekly used dates than CPAP $(6.5 \pm$ 0.4 vs. $5.7 \pm 0.7, \mathrm{p}<0.01)$. However, several other studies have shown no difference in compliance between APAP and CPAP [59-61]. Also, Gay et al. [62] and Reeves-Hoché et al. [63] reported that the compliance is not different between bi-level positive airway pressure (BiPAP) and CPAP. Hukins [64] reported that although compliance is similar between CPAP and APAP used patients, it is higher with APAP in subjects who complained of side effects.

Several studies have evaluated the effect(s) of various interfaces on compliance. Studies conducted by Khanna and Kline [65] and Anderson et al. [66] demonstrated that oral and nasal interfaces did not demonstrate differences in the average number of hours of CPAP use. However, Rowland et al. [67] reported that, although CPAP adherence did not demonstrate a difference between interfaces, patients reported greater mask comfort, better sleep, and overall preference for a nasal mask than an oral mask.
Additionally, Neuzeret and Morin [68] suggested that initial mask selection can influence adherence and healthcare use during CPAP treatment. Massie and Robert [69] reported that a group using a nasal pillow demonstrated a higher percentage of days of use than the group that used a nasal mask ( $94.1 \%$ vs. $85.7 \% ; \mathrm{p}=0.02$ ). Thus, it is crucial to prescribe the optimal interface for successful treatment at the beginning of CPAP therapy.

As mentioned above, nasal or oral dryness are common discomfort during CPAP treatment and reported in approximately $65 \%$ of patients [28]. To treat discomfort, heated humidification has been used. Accordingly, several researchers have investigated the association between heated humidification and compliance with CPAP therapy, with conflicting results. Massie et al. [70] reported that the mean duration of daily CPAP use increased when heated humidification was used $(5.52 \pm 2.1 \mathrm{~h} /$ night vs. $4.93 \pm 2.2 \mathrm{~h} /$ night; $\mathrm{p}=0.001)$. Another study conducted by Soudorn et al. [71] also reported that the mean duration of use significantly increased with heated humidification in patients with moderate to severe OSA $(5.5 \pm 1.5 \mathrm{~h} /$ night vs. $5.2 \pm 1.4 \mathrm{~h} /$ night; $\mathrm{p}=0.033$ ). In contrast, however, Mador et al. [72] conducted a randomized controlled trial with 98 OSA patients who initially received CPAP treatment and reported that additional heated humidification did not lead to better compliance. Ryan et al. [35] conducted a randomized controlled trial that included 125 OSA patients and reported that, although humidification decreased the frequency of nasal dryness, compliance with CPAP therapy was not improved. Additionally, a recently published meta-analysis by Zhu et al. [73] reported that heated humidification did not improve compliance with CPAP treatment. Thus, we suggest that, although heated humidification during CPAP could improve nasal discomfort, it does not necessarily improve compliance with CPAP therapy.

\section{CPAP COMPLIANCE IN CHILDREN}

In general, the initial treatment of choice for pediatric OSA is adenotonsillectomy [74]. However, CPAP treatment may be an alternative therapeutic option in children who experience persistent OSA after surgery or in patients in whom surgery is not recommended or contraindicated [75]. Although CPAP treatment is highly efficacious in pediatric patients with OSA, the compliance rate is low and even in compliant subjects, nightly use is suboptimal. Marcus et al. [13] reported that approximately one-third of patients dropped out before six months, and Xanthopoulos et al. [76] reported that only approximately $21 \%$ of children used CPAP $<20$ min daily at one month after initiation of CPAP. Hawkins et al. [77] conducted a retrospective review of 140 pediatric patients with OSA and reported that approximately 49\% (69/140) demonstrated good compliance. Accordingly, we reviewed the literature pertaining to the assessment of factors associated with pediatric OSA. Several studies 
have performed analyses according to the demographic information of children. Although age is a frequently assessed factor in studies investigating compliance with CPAP therapy in children, we found conflicting results. Lynch et al. [78] conducted a prospective study with 25 pediatric patients with OSA and reported that the group adequately compliant with CPAP therapy was younger than the CPAP non-compliant group (10.53 \pm 2.17 years of age vs. $13.50 \pm 2.32$ years of age, respectively; $\mathrm{p}=0.010$ ). O'Donnell et al. [14] reported that mean daily hours of CPAP use decreased with age (7.2 \pm 3.8 hours vs. $4.2 \pm 2.7$ hours vs. $3.6 \pm 3.1$ hours in $\leq 5,6-12$, and 13-18 years' age groups, respectively; $\mathrm{p}=0.013$ ). Also, Avis et al. [79] reported that the mean age of the adequately compliant CPAP group was younger than the non-compliant group $(10.7 \pm 2.2$ years of age vs. $14.7 \pm 1.1$ years of age; $p<0.01)$. In contrast, several other studies reported that age was not associated with compliance to CPAP therapy $[77,80,81]$.

Several studies have reported that sex was not significantly associated with CPAP compliance [14,78-82]. In contrast, one study by Hawkins et al. [77] reported that female sex was associated with better adherence $[60.9 \%$ vs. 39.5\%; OR 2.41 (95\% CI 1.20-4.85); $\mathrm{p}=0.01]$.

Finally, we also reviewed the literature pertaining to CPAP compliance and OSA severity, with several studies reporting that disease severity was not associated with compliance [14,78,80,81]. However, one study reported that patients adequately compliant with CPAP therapy demonstrated higher baseline AHI than that of non-compliant patients [82]. DiFeo et al. [75] reported that the severity of apnea and pressure level was not associated with adherence to CPAP therapy in a prospective study with 56 patients. They also reported that the greatest predictor of CPAP use was maternal education level, with higher levels associated with better outcome $(r=0.405 ; \mathrm{p}=0.002$ for nights used and $r=0.290 ; \mathrm{p}=0.033$ for mean hours used/night). In contrast, Lynch et al. [78] reported that maternal education level was insignificantly different between the adequately compliant and non-compliant groups. One study investigating the association between self-efficacy using SEMSA and CPAP compliance in pediatric population reported that the SEMSA score and CPAP compliance were significantly associated $(\mathrm{p}=0.007)$, and mean daily CPAP use increased by $48.4 \mathrm{~min}$ with every 1 point increase in the SEMSA score (95\% CI 13.4-83.4 min) [76].

\section{CONCLUSION}

Various factors are associated with compliance with CPAP therapy. Regarding socioeconomic/demographic characteristics, we found that age and sex demonstrated conflicting results, but high SES and Caucasians were associated with good compliance. Nasal disease was significantly associated with compliance to CPAP therapy and treatment of the disease using septo- plasty or turbinoplasty improved compliance with CPAP therapy. However, the administration of intranasal topical steroid demonstrated no benefit in compliance with CPAP therapy. Several investigators reported that upper airway obstruction can lead to increases in CPAP pressure, and oropharyngeal surgery, including UPPP, can reduce CPAP pressure and may also increase compliance. We found that various parameters of OSA severity were significantly associated with CPAP compliance, and that as disease worsened compliance increased. Self-efficacy before CPAP initiation significantly enhanced compliance, and explanation of disease status to patients by viewing their PSG data and TM care could increase the compliance with CPAP therapy. Regarding device-related factors, prescribing the optimal interface is crucial for good compliance, and heated humidification may improve nasal discomfort during CPAP but not necessarily compliance. In children, sex was not associated with better adherence, and disease severity also demonstrated no association. Selfefficacy before initiation of CPAP therapy in children was also significantly associated with compliance.

\section{Acknowledgments}

None.

\section{Conflicts of Interest}

The authors have no financial conflicts of interest.

\section{Authors' Contribution}

Conceptualization: all authors. Formal analysis: Seo MY. Supervision: Lee SH. Writing_original draft: Seo MY. Writing_review \& editing: all authors.

\section{REFERENCES}

1. Marcus CL, Brooks LJ, Draper KA, Gozal D, Halbower AC, Jones J, et al. Diagnosis and management of childhood obstructive sleep apnea syndrome. Pediatrics 2012;130:e714-55.

2. Seo MY, Hwang SJ, Nam KJ, Lee SH. Significance of sleep stability using cardiopulmonary coupling in sleep disordered breathing. Laryngoscope 2019 Nov 21 [Epub]. https://doi.org/10.1002/lary.28379.

3. Seo MY, Lee JY, Hahn JY, Ryu G, Hong SD, Dhong HJ, et al. Association of obstructive sleep apnea with subclinical cardiovascular disease predicted by coronary artery calcium score in asymptomatic subjects. Am J Cardiol 2017;120:577-81.

4. Flemons WW. Measuring health related quality of life in sleep apnea. Sleep 2000;23 Suppl 4:S109-14.

5. Moyer CA, Sonnad SS, Garetz SL, Helman JI, Chervin RD. Quality of life in obstructive sleep apnea: a systematic review of the literature. Sleep Med 2001;2:477-91.

6. Sullivan CE, Issa FG, Berthon-Jones M, Eves L. Reversal of obstructive sleep apnoea by continuous positive airway pressure applied through the nares. Lancet 1981;1:862-5.

7. Rotenberg BW, Murariu D, Pang KP. Trends in CPAP adherence over twenty years of data collection: a flattened curve. J Otolaryngol Head Neck Surg 2016;45:43.

8. Doherty LS, Kiely JL, Swan V, McNicholas WT. Long-term effects of nasal continuous positive airway pressure therapy on cardiovascular outcomes in sleep apnea syndrome. Chest 2005;127:2076-84.

9. Engleman HM, Martin SE, Deary IJ, Douglas NJ. Effect of continuous positive airway pressure treatment on daytime function in sleep apnoea/ hypopnoea syndrome. Lancet 1994;343:572-5. 
10. Marin JM, Carrizo SJ, Vicente E, Agusti AG. Long-term cardiovascular outcomes in men with obstructive sleep apnoea-hypopnoea with or without treatment with continuous positive airway pressure: an observational study. Lancet 2005;365:1046-53.

11. Mehrtash M, Bakker JP, Ayas N. Predictors of continuous positive airway pressure adherence in patients with obstructive sleep apnea. Lung 2019;197:115-21.

12. Weaver TE, Grunstein RR. Adherence to continuous positive airway pressure therapy: the challenge to effective treatment. Proc Am Thorac Soc 2008;5:173-8.

13. Marcus CL, Rosen G, Ward SL, Halbower AC, Sterni L, Lutz J, et al. Adherence to and effectiveness of positive airway pressure therapy in children with obstructive sleep apnea. Pediatrics 2006;117:e442-51.

14. O'Donnell AR, Bjornson CL, Bohn SG, Kirk VG. Compliance rates in children using noninvasive continuous positive airway pressure. Sleep 2006;29:651-8.

15. Kohler M, Smith D, Tippett V, Stradling JR. Predictors of long-term compliance with continuous positive airway pressure. Thorax 2010;65: 829-32.

16. Gulati A, Ali M, Davies M, Quinnell T, Smith I. A prospective observational study to evaluate the effect of social and personality factors on continuous positive airway pressure (CPAP) compliance in obstructive sleep apnoea syndrome. BMC Pulm Med 2017;17:56.

17. Pelletier-Fleury N, Rakotonanahary D, Fleury B. The age and other factors in the evaluation of compliance with nasal continuous positive airway pressure for obstructive sleep apnea syndrome. A Cox's proportional hazard analysis. Sleep Med 2001;2:225-32.

18. May AM, Gharibeh T, Wang L, Hurley A, Walia H, Strohl KP, et al. CPAP adherence predictors in a randomized trial of moderate-to-severe OSA enriched with women and minorities. Chest 2018;154:567-78.

19. Bakker JP, O'Keeffe KM, Neill AM, Campbell AJ. Ethnic disparities in CPAP adherence in New Zealand: effects of socioeconomic status, health literacy and self-efficacy. Sleep 2011;34:1595-603.

20. Billings ME, Auckley D, Benca R, Foldvary-Schaefer N, Iber C, Redline $\mathrm{S}$, et al. Race and residential socioeconomics as predictors of CPAP adherence. Sleep 2011;34:1653-8.

21. Campbell A, Neill A, Lory R. Ethnicity and socioeconomic status predict initial continuous positive airway pressure compliance in New Zealand adults with obstructive sleep apnoea. Intern Med J 2012;42:e95-101.

22. Gagnadoux F, Le Vaillant M, Goupil F, Pigeanne T, Chollet S, Masson $\mathrm{P}$, et al. Influence of marital status and employment status on long-term adherence with continuous positive airway pressure in sleep apnea patients. PLoS One 2011;6:e22503.

23. Simon-Tuval T, Reuveni H, Greenberg-Dotan S, Oksenberg A, Tal A, Tarasiuk A. Low socioeconomic status is a risk factor for CPAP acceptance among adult OSAS patients requiring treatment. Sleep 2009;32: 545-52.

24. Platt AB, Field SH, Asch DA, Chen Z, Patel NP, Gupta R, et al. Neighborhood of residence is associated with daily adherence to CPAP therapy. Sleep 2009;32:799-806.

25. Means MK, Ulmer CS, Edinger JD. Ethnic differences in continuous positive airway pressure (CPAP) adherence in veterans with and without psychiatric disorders. Behav Sleep Med 2010;8:260-73.

26. Budhiraja R, Parthasarathy S, Drake CL, Roth T, Sharief I, Budhiraja P, et al. Early CPAP use identifies subsequent adherence to CPAP therapy. Sleep 2007;30:320-4.

27. Scharf SM, Seiden L, DeMore J, Carter-Pokras O. Racial differences in clinical presentation of patients with sleep-disordered breathing. Sleep Breath 2004;8:173-83.

28. Pépin JL, Leger P, Veale D, Langevin B, Robert D, Lévy P. Side effects of nasal continuous positive airway pressure in sleep apnea syndrome. Study of 193 patients in two French sleep centers. Chest 1995;107:37581.

29. Mickelson SA. Nasal surgery for obstructive sleep apnea syndrome. Otolaryngol Clin North Am 2016;49:1373-81.
30. Sugiura T, Noda A, Nakata S, Yasuda Y, Soga T, Miyata S, et al. Influence of nasal resistance on initial acceptance of continuous positive airway pressure in treatment for obstructive sleep apnea syndrome. Respiration 2007;74:56-60.

31. Inoue A, Chiba S, Matsuura K, Osafune H, Capasso R, Wada K. Nasal function and CPAP compliance. Auris Nasus Larynx 2019;46:548-558.

32. Park P, Kim J, Song YJ, Lim JH, Cho SW, Won TB, et al. Influencing factors on CPAP adherence and anatomic characteristics of upper airway in OSA subjects. Medicine (Baltimore) 2017;96:e8818.

33. Camacho M, Riaz M, Capasso R, Ruoff CM, Guilleminault C, Kushida $\mathrm{CA}$, et al. The effect of nasal surgery on continuous positive airway pressure device use and therapeutic treatment pressures: a systematic review and meta-analysis. Sleep 2015;38:279-86.

34. Powell NB, Zonato AI, Weaver EM, Li K, Troell R, Riley RW, et al. Radiofrequency treatment of turbinate hypertrophy in subjects using continuous positive airway pressure: a randomized, double-blind, placebo-controlled clinical pilot trial. Laryngoscope 2001;111:1783-90.

35. Ryan S, Doherty LS, Nolan GM, McNicholas WT. Effects of heated humidification and topical steroids on compliance, nasal symptoms, and quality of life in patients with obstructive sleep apnea syndrome using nasal continuous positive airway pressure. J Clin Sleep Med 2009; 5:422-7.

36. Strobel W, Schlageter M, Andersson M, Miedinger D, Chhajed PN, Tamm M, et al. Topical nasal steroid treatment does not improve CPAP compliance in unselected patients with OSAS. Respir Med 2011;105: 310-5.

37. Masdon JL, Magnuson JS, Youngblood G. The effects of upper airway surgery for obstructive sleep apnea on nasal continuous positive airway pressure settings. Laryngoscope 2004;114:205-7.

38. Kim HY, Min JY, Cho DY, Chung SK, Dhong HJ. Influence of upper airway narrowing on the effective continuous positive airway pressure level. Laryngoscope 2007;117:82-5.

39. Hong SD, Kim HY, Cho HJ, Jang MS, Dhong HJ, Chung SK. Effect of uvulopalatopharyngoplasty on CPAP compliance. Eur Arch Otorhinolaryngol 2015;272:1437-42.

40. Azbay S, Bostanci A, Aysun Y, Turhan M. The influence of multilevel upper airway surgery on CPAP tolerance in non-responders to obstructive sleep apnea surgery. Eur Arch Otorhinolaryngol 2016;273:2813-8.

41. Zonato AI, Bittencourt LR, Martinho FL, Gregório LC, Tufik S. Upper airway surgery: the effect on nasal continuous positive airway pressure titration on obstructive sleep apnea patients. Eur Arch Otorhinolaryngol 2006;263:481-6.

42. Riachy M, Najem S, Iskandar M, Choucair J, Ibrahim I, Juvelikian G. Factors predicting CPAP adherence in obstructive sleep apnea syndrome. Sleep Breath 2017;21:295-302.

43. Campos-Rodriguez F, Martinez-Alonso M, Sanchez-de-la-Torre M, Barbe F; Spanish Sleep Network. Long-term adherence to continuous positive airway pressure therapy in non-sleepy sleep apnea patients. Sleep Med 2016;17:1-6.

44. Baratta F, Pastori D, Bucci T, Fabiani M, Fabiani V, Brunori M, et al. Long-term prediction of adherence to continuous positive air pressure therapy for the treatment of moderate/severe obstructive sleep apnea syndrome. Sleep Med 2018;43:66-70.

45. Stepnowsky CJ Jr, Marler MR, Ancoli-Israel S. Determinants of nasal CPAP compliance. Sleep Med 2002;3:239-47.

46. Weaver TE, Maislin G, Dinges DF, Younger J, Cantor C, McCloskey S, et al. Self-efficacy in sleep apnea: instrument development and patient perceptions of obstructive sleep apnea risk, treatment benefit, and volition to use continuous positive airway pressure. Sleep 2003;26:727-32.

47. Baron KG, Berg CA, Czajkowski LA, Smith TW, Gunn HE, Jones CR. Self-efficacy contributes to individual differences in subjective improvements using CPAP. Sleep Breath 2011;15:599-606.

48. Sawyer AM, Canamucio A, Moriarty H, Weaver TE, Richards KC, Kuna ST. Do cognitive perceptions influence CPAP use? Patient Educ Couns 2011;85:85-91. 
49. Philip P, Bioulac S, Altena E, Morin CM, Ghorayeb I, Coste O, et al. Specific insomnia symptoms and self-efficacy explain CPAP compliance in a sample of OSAS patients. PLoS One 2018;13:e0195343.

50. Meurice JC, Ingrand P, Portier F, Arnulf I, Rakotonanahari D, Fournier $\mathrm{E}$, et al. A multicentre trial of education strategies at CPAP induction in the treatment of severe sleep apnoea-hypopnoea syndrome. Sleep Med 2007;8:37-42.

51. Hui DS, Chan JK, Choy DK, Ko FW, Li TS, Leung RC, et al. Effects of augmented continuous positive airway pressure education and support on compliance and outcome in a Chinese population. Chest 2000;117: 1410-6.

52. Bouloukaki I, Giannadaki K, Mermigkis C, Tzanakis N, Mauroudi E, Moniaki V, et al. Intensive versus standard follow-up to improve continuous positive airway pressure compliance. Eur Respir J 2014;44:126274.

53. Hoy CJ, Vennelle M, Kingshott RN, Engleman HM, Douglas NJ. Can intensive support improve continuous positive airway pressure use in patients with the sleep apnea/hypopnea syndrome? Am J Respir Crit Care Med 1999;159:1096-100.

54. Chen C, Wang J, Pang L, Wang Y, Ma G, Liao W. Telemonitor care helps CPAP compliance in patients with obstructive sleep apnea: a systemic review and meta-analysis of randomized controlled trials. Ther $A d v$ Chronic Dis 2020;11:2040622320901625.

55. Jurado-Gamez B, Bardwell WA, Cordova-Pacheco LJ, García-Amores M, Feu-Collado N, Buela-Casal G. A basic intervention improves CPAP adherence in sleep apnoea patients: a controlled trial. Sleep Breath 2015;19:509-14.

56. Falcone VA, Damiani MF, Quaranta VN, Capozzolo A, Resta O. Polysomnograph chart view by patients: a new educational strategy to improve CPAP adherence in sleep apnea therapy. Respir Care 2014;59:193-8.

57. Massie CA, McArdle N, Hart RW, Schmidt-Nowara WW, Lankford A, Hudgel DW, et al. Comparison between automatic and fixed positive airway pressure therapy in the home. Am J Respir Crit Care Med 2003; 167:20-3.

58. Konermann M, Sanner BM, Vyleta M, Laschewski F, Groetz J, Sturm A, et al. Use of conventional and self-adjusting nasal continuous positive airway pressure for treatment of severe obstructive sleep apnea syndrome: a comparative study. Chest 1998;113:714-8.

59. d'Ortho MP, Grillier-Lanoir V, Levy P, Goldenberg F, Corriger E, Harf A, et al. Constant vs. automatic continuous positive airway pressure therapy: home evaluation. Chest 2000;118:1010-7.

60. Hudgel DW, Fung C. A long-term randomized, cross-over comparison of auto-titrating and standard nasal continuous airway pressure. Sleep 2000;23:645-8.

61. Teschler H, Wessendorf TE, Farhat AA, Konietzko N, Berthon-Jones $\mathrm{M}$. Two months auto-adjusting versus conventional nCPAP for obstructive sleep apnoea syndrome. Eur Respir J 2000;15:990-5.

62. Gay PC, Herold DL, Olson EJ. A randomized, double-blind clinical trial comparing continuous positive airway pressure with a novel bilevel pressure system for treatment of obstructive sleep apnea syndrome. Sleep 2003;26:864-9.

63. Reeves-Hoché MK, Hudgel DW, Meck R, Witteman R, Ross A, Zwillich CW. Continuous versus bilevel positive airway pressure for obstructive sleep apnea. Am J Respir Crit Care Med 1995;151:443-9.

64. Hukins C. Comparative study of autotitrating and fixed-pressure CPAP in the home: a randomized, single-blind crossover trial. Sleep 2004;27:1512-7.

65. Khanna R, Kline LR. A prospective 8 week trial of nasal interfaces vs. a novel oral interface (Oracle) for treatment of obstructive sleep apnea hypopnea syndrome. Sleep Med 2003;4:333-8.
66. Anderson FE, Kingshott RN, Taylor DR, Jones DR, Kline LR, Whyte KF. A randomized crossover efficacy trial of oral CPAP (Oracle) compared with nasal CPAP in the management of obstructive sleep apnea. Sleep 2003;26:721-6.

67. Rowland S, Aiyappan V, Hennessy C, Catcheside P, Chai-Coezter CL, McEvoy RD, et al. Comparing the efficacy, mask leak, patient adherence, and patient preference of three different CPAP interfaces to treat moderate-severe obstructive sleep apnea. J Clin Sleep Med 2018;14: 101-8.

68. Neuzeret PC, Morin L. Impact of different nasal masks on CPAP therapy for obstructive sleep apnea: a randomized comparative trial. Clin Respir J 2017;11:990-8.

69. Massie CA, Robert WH. Clinical outcomes related to interface type in patients with obstructive sleep apnea/hypopnea syndrome who are using continuous positive airway pressure. Chest 2003;123:1112-8.

70. Massie CA, Hart RW, Peralez K, Richards GN. Effects of humidification on nasal symptoms and compliance in sleep apnea patients using continuous positive airway pressure. Chest 1999;116:403-8.

71. Soudorn C, Muntham D, Reutrakul S, Chirakalwasan N. Effect of heated humidification on CPAP therapy adherence in subjects with obstructive sleep apnea with nasopharyngeal symptoms. Respir Care 2016;61: $1151-9$.

72. Mador MJ, Krauza M, Pervez A, Pierce D, Braun M. Effect of heated humidification on compliance and quality of life in patients with sleep apnea using nasal continuous positive airway pressure. Chest 2005;128: 2151-58.

73. Zhu D, Wu M, Cao Y, Lin S, Xuan N, Zhu C, et al. Heated humidification did not improve compliance of positive airway pressure and subjective daytime sleepiness in obstructive sleep apnea syndrome: a meta-analysis. PLoS One 2018;13:e0207994.

74. Section on Pediatric Pulmonology and Subcommittee on Obstructive Sleep Apnea Syndrome. Clinical practice guideline: diagnosis and management of childhood obstructive sleep apnea syndrome. Pediatrics 2002;109:704-12.

75. DiFeo N, Meltzer LJ, Beck SE, Karamessinis LR, Cornaglia MA, Traylor J, et al. Predictors of positive airway pressure therapy adherence in children: a prospective study. J Clin Sleep Med 2012;8:279-86.

76. Xanthopoulos MS, Kim JY, Blechner M, Chang MY, Menello MK, Brown C, et al. Self-efficacy and short-term adherence to continuous positive airway pressure treatment in children. Sleep 2017;40.

77. Hawkins SM, Jensen EL, Simon SL, Friedman NR. Correlates of pediatric CPAP adherence. J Clin Sleep Med 2016;12:879-84.

78. Lynch MK, Elliott LC, Avis KT, Schwebel DC, Goodin BR. Quality of life in youth with obstructive sleep apnea syndrome (OSAS) treated with continuous positive airway pressure (CPAP) therapy. Behav Sleep Med 2019;17:238-45.

79. Avis KT, Gamble KL, Schwebel DC. Effect of positive airway pressure therapy in children with obstructive sleep apnea syndrome: does positive airway pressure use reduce pedestrian injury risk? Sleep Health 2019;5:161-5.

80. Machaalani R, Evans CA, Waters KA. Objective adherence to positive airway pressure therapy in an Australian paediatric cohort. Sleep Breath 2016;20:1327-36

81. Nixon GM, Mihai R, Verginis N, Davey MJ. Patterns of continuous positive airway pressure adherence during the first 3 months of treatment in children. J Pediatr 2011;159:802-7.

82. Uong EC, Epperson M, Bathon SA, Jeffe DB. Adherence to nasal positive airway pressure therapy among school-aged children and adolescents with obstructive sleep apnea syndrome. Pediatrics 2007;120:e120311 . 